\title{
Forensic Investigation of Bullet Holes for Determining Distance from Glass Fracture Analysis
}

\author{
Butt $A^{1 *}$, Ali $A^{1}$, Ahmad $A^{2}$, Shehzad $M^{3}$ and Malik \\ $\mathbf{A}^{\mathbf{1}}$ \\ ${ }^{1}$ Institute of Molecular Biology and Biotechnology \\ (IMBB), The University of Lahore, Lahore, Pakistan \\ ${ }^{2}$ Firearms \& Tool Marks Section, National Forensic \\ Science Agency (NFSA), Islamabad, Pakistan \\ ${ }^{3}$ Govt. Graduate College, Model Town Lahore, Lahore, \\ Pakistan \\ *Corresponding author: Aisha Butt, Institute of \\ Molecular Biology and Biotechnology (IMBB), The \\ University of Lahore, Lahore, Pakistan
}

Received: February 26, 2021; Accepted: April 08, 2021; Published: April 15, 2021

\begin{abstract}
The study of glass fracture patterns has been of long interest to the forensic community. Fragments of glass can be significant evidence found in the investigation of various types of offenses especially where armed violence is involved on automobiles. Figuring out, whether glass fragments present on crime scene share the same origin as per glass that has been hit by a projectile or any substrate, is quite a success to an examiner because that further leads to the investigation of how and by which means it has done. Holes occurred in the glass at the crime scenes have much importance and many attempts are taken to investigate the properties of these glass holes to find the type, speed, and angle of the projectile which probably produce the hole. For highvelocity projectiles including bullets, these bullet holes in glass can exhibit certain features and fractures. The objective of this research was to determine the distance of shooter from the bullet hole on glass used in automobiles. Bullet holes were prepared and different parameters of glass fractures like bullet hole diameter, cone fractures radius, cone fractures diameter, radial, and concentric fracture count were considered from both front and the backside of the glass. These parameters were observed and analyzed to determine the dependency of these parameters on the variable "distance". The consistency found in the measurements to conclude our results were checked by goodness of fit test. The study bears great significance as it could lay down a foundation to set a standard parameter to estimate distance of bullet hole from shooter in firing incidents involving glass fracture. This will provide a blueprint to crime scene investigators in order to reconstruct the crime scene for understanding and to take investigation to logical conclusion.
\end{abstract}

Keywords: Fracture pattern analysis; Bullet hole investigation; Hole diameter; Low-velocity firearm (pistol); High-velocity firearm (rifle); Hole diameter, Laminated glass; Tempered glass

\section{Introduction}

Fragments of glass are substantial physical evidence found in different kinds of scenes in an investigation. Such cases where firearms are involved, glass fractures may provide valuable information related to what happened and help in investigating the crime scene [1]. Glass can be fractured intentionally or unintentionally at the crime scenes. The forensic community has been interested in fracture pattern for long now, as analysis of glass fracture pattern known as "fractography" is very helpful to create link and sequence between events that occurred and evidence that was available on the crime scene [2]. The use of firearms especially improvised firearms and reloaded ammunition in criminal activities has been an alarming situation for law enforcement agencies. Analysis of glass fracture pattern often provides much significant information like causes of fracture, the direction of a bullet hitting the target, impact on fracture pattern from distance and direction, etc.

In criminal examinations, valuable data can be interpreted through understanding and assessment of glass cracks. Crack surfaces can be legitimately associated with the way glass objects are broken, hence revealing much information about the crime that has occurred. This relativity was credibly shown by research that has previously been conducted. Often forensic scientist has to look back further to process the applied stress with the external forces due to which fracture has been followed. Those forces include the impact of blunt objects at relatively low velocity and high velocity considering bullet impacts are mainly of forensic interest. Glass breakage is studied depending on the nature of crime scene, as other than impact forces; if crime scene involves arson case then thermal stresses may also be a reason to cause the fracture.

While analyzing the origin of fractures, Richard [3], presented crack patterns of fracture found to be in accordance with previous studies. He found first surface feature to be mirror zone that is the smooth region. After that, the rough region starts with not very defined boundary but it can be easily distinguished from smooth region known as the mist region. After the mist region, further instability leads towards the hackle region. These are the radiating lines away from the fracture origin but are not very definitive as radial cracks and can lead towards the mist region back to mirror region and origin of fracture. These regions are formed concentrically all around the impact point and can be said to appear in the fracture process as its occurrence pattern.

Md. Ansari [4] while studying the influence the influence of 
projectile nose shape and angled fire damage on laminated glass fiber, observed the impact caused on laminated glass that as the shape of the projectile was changed from conical to blunt the damaging impact was increased.

Much work has been done in recent years on glass fracture pattern analysis on window panes by an air rifle [2]. It was found that their high-velocity projectiles caused bullet hole, double of their calibre size while pistol projectile caused somewhat nearby size of the calibre. Whereas in case of improvised weapon, hole diameter was found in a greater number of variations.

To know the effect of change in pellet shape; a study was conducted [5] and found a consistent range in hole diameter formed due to both types of pellet shape: round nose and flattened nose. The identification of pellet shape from studying fracture pattern of hole diameter and shape of hole diameter was not possible.

Another study was done with air rifle on window panes of different thickness than in previous one to study multiple fractures [6]. Difference in hole diameter was found; it was concluded that hole diameter of first shot was larger than that of second shot in the transparent glass of $4 \mathrm{~mm}$, and $5 \mathrm{~mm}$ thickness. Whereas in the type; privacy glass of $4 \mathrm{~mm}$ thickness the hole diameter of second shot was larger than the hole diameter of first shot. These point are said to be indicative for the study of multiple fractures.

A research [7] was carried out to study effect of high velocity projectile on window panes and observed the fracture pattern consistent with the prior findings. It also established that increase in distance for some meters does not change the impact that much.

With all the literature review it was observed that little work has been done for analysis of bullet holes on automobile glass for determining distance. For this purpose this research has been a novel and pioneer step in forensic science regarding the reconstruction of crime scene. This research is focused on the bullet hole investigation for determining distance of the shooter from target on the glass that are used in automobiles i.e., laminated glass and tempered glass. When automobiles are present as primary or secondary evidence in crime scenes where firearms were involved, most likely glass pieces are present as evidence inside the automobile and outside as well. Glass pieces can be caused due to some accidental breakage or in case of firearms involvement; these pieces can be of bullet holes present in the glass. Bullet hole and its impact vary according to the target; in case where target is glass, bullet hole and its fractures give a pattern. This pattern contains similar type of features like bullet hole shape, cone fractures, radial \& concentric fractures; by analyzing these features different parameters can be calculated about the crime. To evaluate the dependency of bullet hole and its fractures pattern on distance, this research was conducted. Firearms and its ammunition that are frequently used in shooting cases in Pakistan are considered in this research.

The analysis had done by studying the bullet hole and its features occurring on the surface and present around the bullet hole along with the three types of fracture pattern i.e., radial, concentric and cone fractures along with other surface features. When a projectile hits the glass it causes two distinct fractures, radial and concentric. Cone fractures are observed to be caused by the penetration of high- velocity projectile, such as a bullet. As Griffiths states in his fracture experiment that fractures always start from pre-existing flaws that are termed as Griffith's flaw [6].

Parameter like change in distance also gives variety in impact pattern of bullet on glass. For this purpose bullet holes were prepared from four different distances and compared their results. To analyze bullet hole and its impact, complete glass fracture analysis was done. It was analyzed whether change in distance effect the fracture measurements or not. Change in specific interval of distance gives certain amount of difference in Measurements and these measurements were analyzed to make conclusive statement about the determination of distance with help of bullet hole analysis.

\section{Materials and Methodology}

Main focus was the analysis of bullet hole on automobile glass in this research. Automobile glass consists of two types of glass: tempered glass and laminated glass. Tempered glass is used in automobiles passenger windows and back screen (rear windshield). It is used there as safety glass because in case of any kind of accident it does not harm the passengers due to its break pattern [8].

Laminated glass; the other type used in this research is a type of glass in which plastic interlayer is a sandwich between two sheets of float glass that is done by heating in an autoclave. Thus, in event of impact; laminated glass remains intact by an interlayer, and if breakage occurs its glass pieces remain stuck to the plastic interlayer, thus protecting the passengers from injury. For this reason, automotive laminated glass is used in windshields [9].

To prepare bullet holes, four different calibre firearms that are most commonly available in crime scenes of Pakistan with their typical ammunition available in the open market were taken into account. Locally made pistols, firearms, and their ammunition are very common. .30 bore pistol $(7.62 \times 25 \mathrm{~mm}$ Tokarev), $9 \mathrm{~mm}$ pistol (9x19 mm Parabellum) and AK-47 rifle (7.62x39 mm assault rifle) are the ones mostly involved in crime cases. These all firearms were semi-automatic firearms in which .30 bore pistol, $9 \mathrm{~mm}$ pistol were of recoil mechanism where AK-47 used was of recoil firing mechanism. All ammunitions used for pistols and rifles were fully metal jacketed, centre fire, lead round and bottleneck case that consists of singlebase propellant. (Hays and Jenzen-Jones, 2018) These firearms and ammunitions shown (Figure 1) below were used to perform experimentation on automobile glass.

In order to prepare bullet holes test fires were performed by specialized shooters in outdoor firing range of police line and indoor firing range of National Forensic Science Agency. Measuring tape was used to mark the distance from which a bullet hole was to be prepared. After the bullet holes were prepared, they were labeled with sticky notes and photographed by high speed shutter camera. Measurements for bullet holes were measured by using vernier caliper, standard measuring scale, and screw gauge.

Bullet holes were prepared by performing test fire with mentioned ammunition \& firearms on both: laminated glass and tempered glass in firing range by specialized shooters. The screen was held by support and location of shooter was marked for four different distances to fire on laminated glass. Glass was set on a certain height where it became parallel to the muzzle and was placed at $90^{\circ}$ to muzzle of the weapon 


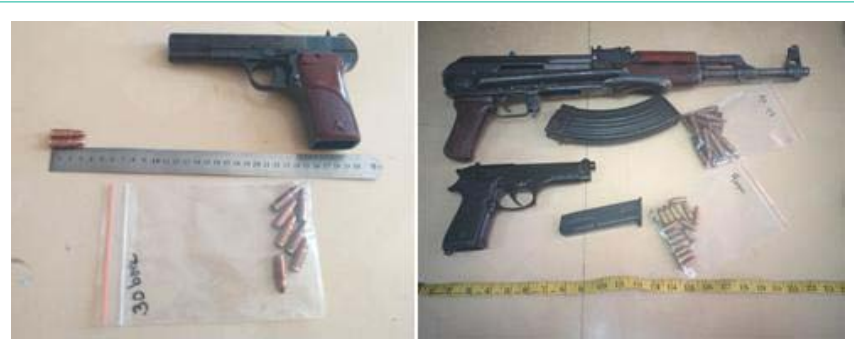

Figure 1: Firearms and ammunitions used in this research.

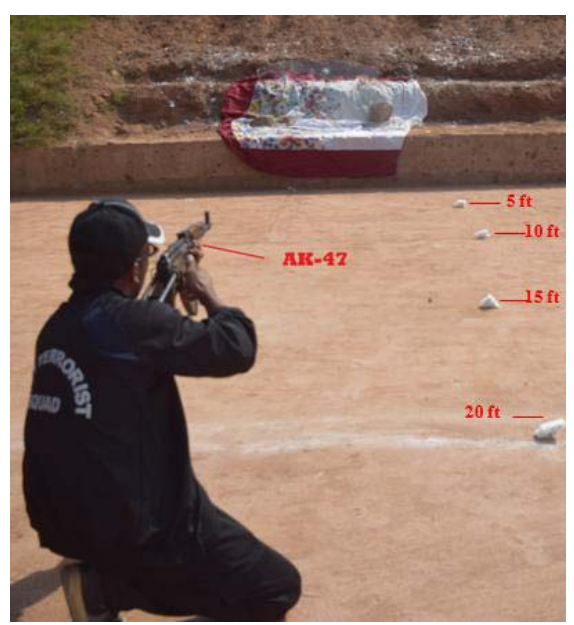

Figure 2: Four tagging displaying distances taken as A, B, C \& D for tempered \& laminated glass.

as shown (Figure 2). Safety precautions were taken into account and test fires were performed under the supervision of experts in firing range.

Bullet holes were prepared from four distances taken as $\mathrm{A}=5 \mathrm{ft}$, $\mathrm{B}=10 \mathrm{ft}, \mathrm{C}=15 \mathrm{ft}, \& \mathrm{D}=20 \mathrm{ft}$ as shown in (Figure 2). While the distance was varying, the other two variables; calibre and angle were fixed. For this purpose .30 bore pistol was used and angle was taken $90^{\circ}$ on each of the four distances to prepare the bullet holes. Noting " 1 " was given to caliber .30 bore and " $\alpha$ " was for $90^{\circ}$ angle. Four bullet holes to be made were $1 \alpha \mathrm{A}, 1 \mathrm{\alpha B}, 1 \mathrm{\alpha C}, \& 1 \mathrm{\alpha D}$ and their measurements were to be noted and compared. These bullet holes were labeled and photographed at each step.

Complete set of data are represented in supplementary. Two measurements for hole diameter, cone fracture diameter from both front and the back side were taken. Two measurements represent the maximum and minimum values as the bullet hole has some irregularities and was not exact circular. In order to be more precise with each reading single operator did the measurements. Each value even for minimum or maximum side of one parameter was measured thrice via vernier calliper and then their mean was taken to minimize human error. For cone fractures radius, two measurements represent the Left (L) and Right (R) side of the bullet hole from the centre point. Now again the measurements were taken thrice and then mean was taken for left and right side of the bullet hole. Where radial and concentric fractures were counted zone wise, count was done three times from front and the back side of the glass and was mentioned

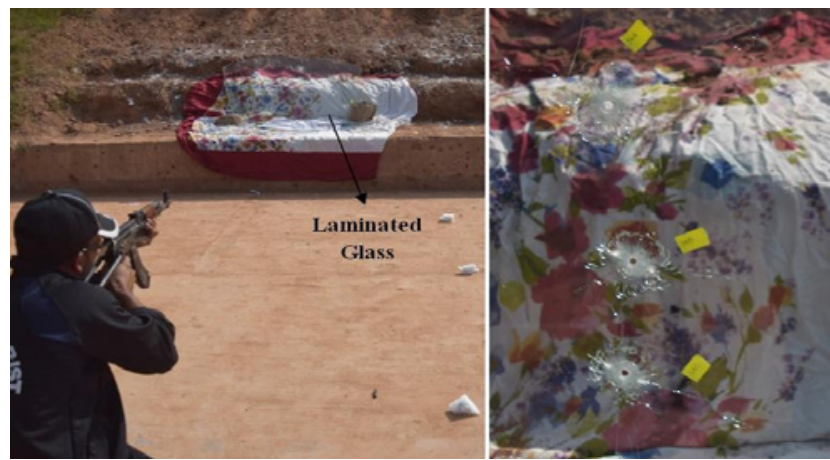

Figure 3: Laminated glass exhibiting clear bullet holes and their fractures.

as it is. As glass flaking can have little uncertainty towards results, so to be sure about the measurements, same distance shot with same pistol and angle was repeated three times. The measurements taken afterwards have followed the same path of measuring each parameter thrice for minimum and maximum values by same single operator just to avoid any human error. As the measurements were taken from vernier caliper the difference in same parameter measurement for all three shots was below $1 \mathrm{~mm}$ that was covered as we have taken the mean of all the measurements to avoid any such uncertainty.

To verify the dependency of bullet holes and their impact is on distance and not on calibre or any other related factor, the same experiments were conducted for other two calibres: $9 \mathrm{~mm}$ pistol, \& AK-47 rifle as well. Same distances were taken in account. Noting "2" and " 3 " was given to $9 \mathrm{~mm}$ pistol and AK-47 rifle respectively and " $\alpha$ " was for $90^{\circ}$ angle. Four bullet holes to be made with $9 \mathrm{~mm}$ pistol were $2 \alpha \mathrm{A}, 2 \alpha \mathrm{B}, 2 \alpha \mathrm{C}, \& 2 \alpha \mathrm{D}$, while with $\mathrm{AK}-47$ rifle were $3 \alpha \mathrm{A}, 3 \alpha \mathrm{B}, 3 \alpha \mathrm{C}, \&$ $3 \alpha \mathrm{D}$ and their measurements were to be noted and compared. These bullet holes were labeled and photographed at each step as done for previous firearm. Same procedure was followed for tempered glass, as it was for laminated glass.

\section{Results}

\section{Laminated glass analysis}

Bullet holes were prepared on laminated glass by all mentioned fires in methodology section and shown in (Figure 3). In contrast to tempered glass, all bullet holes on the laminated glass gave a clear pattern of the bullet hole and its fractures \& features. These features were measured and analyzed to determine the difference in these readings and factors affecting these readings. As laminated glass has glass on the both sides, the bullet hole impact and its fractures also produced on either sides of the glass. And for the same features there was a difference in readings of both sides. So it was kept in mind while measuring and especially while comparing and analyzing those specific readings that were affecting the determination of distance.

\section{Fracture pattern analysis for distance determination:}

For .30 bore pistol: For distance determination, .30 bore was fired on all four distances: A, B, C \& D at $\alpha=90^{\circ}$. Bullet holes: $1 \alpha \mathrm{A}$, $1 \alpha \mathrm{B}, 1 \alpha \mathrm{C}, \& 1 \alpha \mathrm{D}$ were prepared in which $\mathrm{A}=5 \mathrm{ft}, \mathrm{B}=10 \mathrm{ft}, \mathrm{C}=15 \mathrm{ft} \&$ $\mathrm{D}=20 \mathrm{ft}$ as shown in Figure 4 and 5, complete readings of these are mentioned in (Supplementary Table 1).

Cone fractures diameter measurements were giving pattern, as 


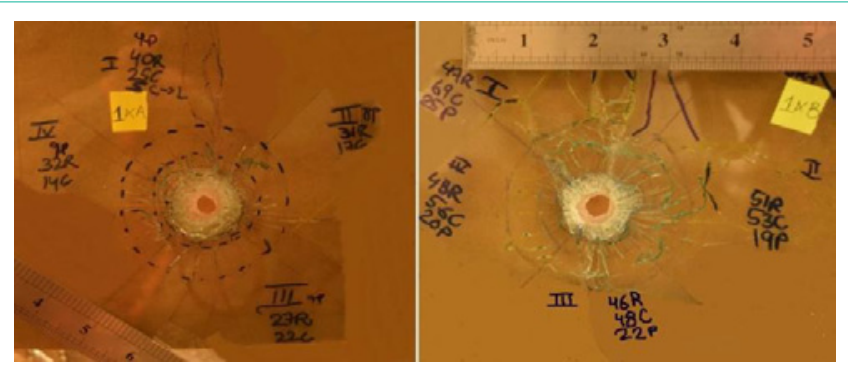

Figure 4: Bullet holes prepared from .30 bore pistol (1) on angle $90^{\circ}(\alpha)$ for each of the four distances. Left: $A=5 \mathrm{ft}$, Right: $B=10 \mathrm{ft}$.

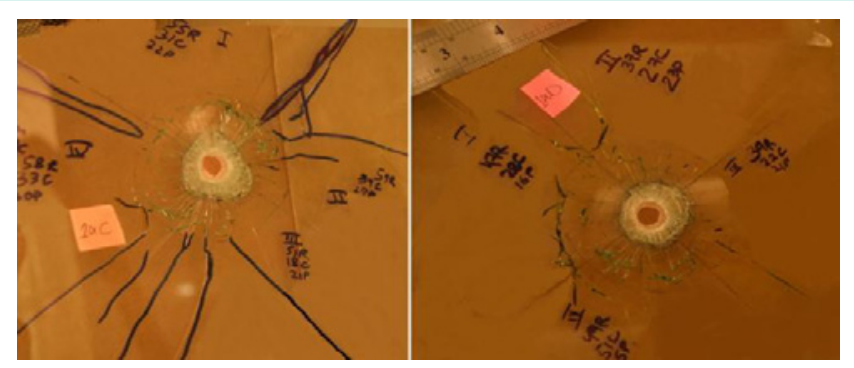

Figure 5: Bullet holes prepared from .30 bore pistol (1) on angle $90^{\circ}(\alpha)$ for each of the four distances. Left: $C=15 \mathrm{ft}$ and Right: $\mathrm{D}=2 \mathrm{fft}$.

they were decreasing with an increase in distance. Cone fractures were decreasing but not in regular intervals, from the front and the back side of the glass. While with an increase in distance, cone fractures radius were decreasing with regular intervals from the front and the back side of the glass.

Radial fractures were observed in all four zones, counted from the front and back in each zone and mentioned in the column zone wise. In some bullet holes for each zone, radial fractures were evenly distributed but this pattern was not consistent with bullet holes on further distances. Neither they were collectively consistent for all distance nor separately in zones. So radial fractures were not consistent in a pattern, hence they can't be useful in distance determination.

Concentric fractures were also observed in each of four zones, counted from front and back and mentioned in column zone wise. Concentric fractures count was not consistent zone wise for all distances and by adding the count of all four zones still, no consistency was established so for determining distance, concentric fractures are not constructive as well.

Comparison: With the change in distance, a consistent pattern was established in bullet hole diameter, and cone fractures radius. Hole diameter is the major parameter that gives us information about

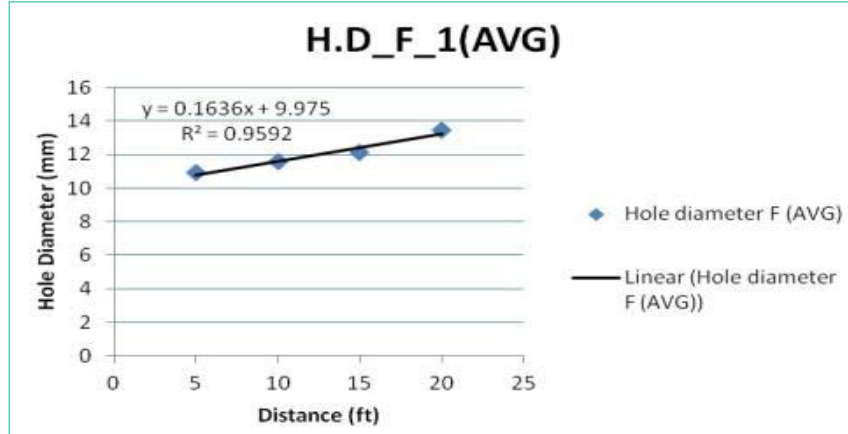

Figure 6: The $x$-axis gives each of the four distances. $A=5 \mathrm{ft}, B=10 \mathrm{ft}, C=15 \mathrm{ft}$, $D=20 f t$ for .30 bore pistol (1). The points for $Y$-axis displaying the hole diameter average value from front side of the laminated glass. The straight line represents the continuity \& increase in the measurements with respect to the distance.

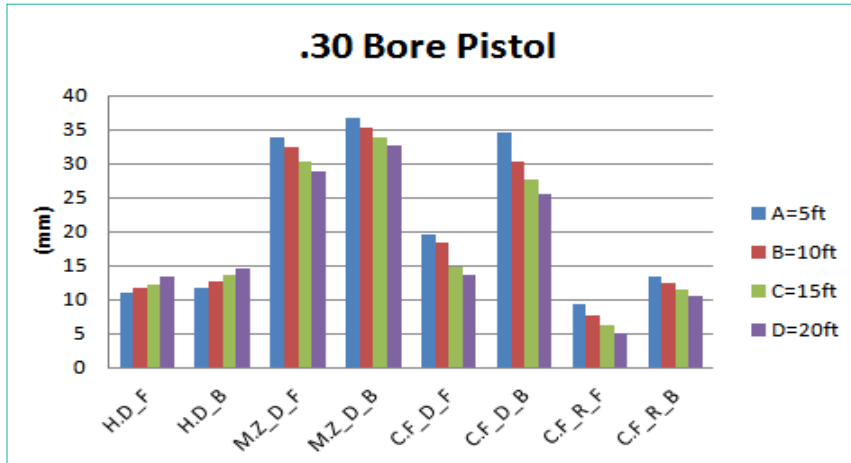

Figure 7: On $\mathrm{x}$-axis four color (Blue, maroon, green, and purple) represents the distance $A=5 \mathrm{ft}, \mathrm{B}=10 \mathrm{ft}, \mathrm{C}=15 \mathrm{ft}, \mathrm{D}=20 \mathrm{ft}$ respectively. On y-axis each parameter measurements in $\mathrm{mm}$ (supplementary) from front and the back sides are considered against all the four distances.

distance of projectile if and only if the calibre and firearm is known and angle shall be $90^{\circ}$ with the plane of the target.

For determining distance, the average of hole diameter from front and back was analyzed but only measurements of hole diameter from the front side i.e., the impact side for .30 bore are shown in (Table 1). Average of bullet hole diameter from front side measurements were taken and mentioned in Table 1 and a consistent pattern was found in increase of these measurements.

In figure (Figure 6), measurements for hole diameter, front measurements of ammunition .30 bore pistol (1) on all four distances while angle was $90^{\circ}(\alpha)$ with the plane of the target, are presented. On $\mathrm{X}$-axis are bullet holes on four distance where $\mathrm{A}=5 \mathrm{ft}, \mathrm{B}=10 \mathrm{ft}, \mathrm{C}=15 \mathrm{ft}$, \& $\mathrm{D}=20 \mathrm{ft}$. On $\mathrm{Y}$-axis are measurements of bullet hole diameter

Table 1: Significant measurements (Hole diameter average) representing the increase in pattern from front side of the glass for .30 bore pistol denoted as (1), $9 \mathrm{~mm}$ pistol denoted as (2), AK-47 rifle denoted as (3) on each of the four distances. $\left(A=5 \mathrm{ft}, \mathrm{B}=10 \mathrm{ft}, \mathrm{C}=15 \mathrm{ft}, \mathrm{D}=20 \mathrm{ft}\right.$ where angle is $90^{\circ} \mathrm{denoted}$ as $(\alpha)$. $\mathrm{F}=\mathrm{Front}$ Side/lmpact side of the glass).

\begin{tabular}{|c|c|c|c|c|c|c|}
\hline \multirow{2}{*}{ Sr. No. } & Bullet holes & Hole diameter $\mathrm{F}$ & Bullet holes & Hole diameter F & Bullet holes & Hole diameter $\mathrm{F}$ \\
\hline & .30 Bore Pistol & AVG & 9x19 mm Pistol & AVG & $7.62 \times 39 \mathrm{~mm}$ Rifle & AVG \\
\hline 1 & $1 \alpha A$ & $10.9 \mathrm{~mm}$ & $2 \alpha A$ & $10.12 \mathrm{~mm}$ & $3 \alpha A$ & $12.43 \mathrm{~mm}$ \\
\hline 2 & $1 \alpha B$ & $11.6 \mathrm{~mm}$ & $2 \alpha B$ & $10.65 \mathrm{~mm}$ & $3 \alpha B$ & $12.97 \mathrm{~mm}$ \\
\hline 3 & $1 \alpha C$ & $12.13 \mathrm{~mm}$ & $2 \alpha C$ & $11.13 \mathrm{~mm}$ & $3 \propto C$ & $13.55 \mathrm{~mm}$ \\
\hline 4 & $1 \alpha D$ & $13.45 \mathrm{~mm}$ & $2 \alpha D$ & $11.5 \mathrm{~mm}$ & $3 \propto D$ & $14 \mathrm{~mm}$ \\
\hline
\end{tabular}




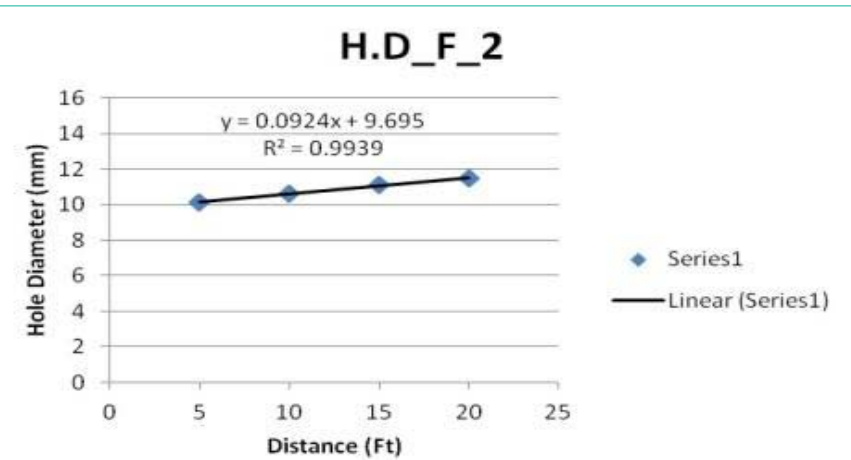

Figure 8: The $x$-axis gives each of the four distances: $A=5 \mathrm{ft}, B=10 \mathrm{ft}, C=15 \mathrm{ft}$, $\mathrm{D}=20 \mathrm{ft}$ for $9 \mathrm{~mm}$ pistol (2). The points for $\mathrm{Y}$-axis displaying the hole diameter average value from front side of the laminated glass. The straight line represents the continuity \& increase in the measurements with respect to the distance.

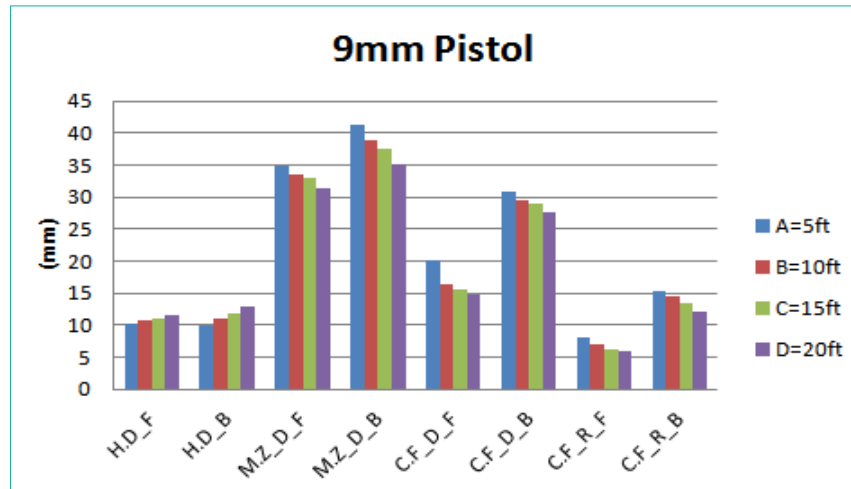

Figure 9: On $\mathrm{x}$-axis four color (Blue, maroon, green, and purple) represents the distance $A=5 \mathrm{ft}, \mathrm{B}=10 \mathrm{ft}, \mathrm{C}=15 \mathrm{ft}, \mathrm{D}=20 \mathrm{ft}$ respectively. On $\mathrm{y}$-axis each parameter measurements in $\mathrm{mm}$ (supplementary) from front and the back sides are considered against all the four distances.

average from the front side of the glass. In this figure, dots represent the measurements for ammunition on respective distance while the straight trend line represents the consistency and continuity in an increase of measurements as the distance is increased. To determine distance from bullet hole diameter measurements, an unknown value (x) can be plotted in this graph and respective distance for that value can be determined from it. The bar chart represents the direct and inverse proportionality for each of the parameter measurements against all the four distances that were considered for .30 bore pistol. Clearly it was observed that while hole diameter front and back both were directly proportional to the increase in distance, other parameters like mist zone diameter front and back, cone fracture diameter front and back, cone fracture radius front and back respectively were inversely proportional to the increase in distance as shown in (Figure 7).

For 9mm pistol: For distance determination, to verify the results of .30 bore pistol, now $9 \mathrm{~mm}$ pistol was fired on all four distances at $\alpha=90^{\circ}$. Bullet holes: $2 \alpha \mathrm{A}, 2 \alpha \mathrm{B}, 2 \alpha \mathrm{C}, \& 2 \alpha \mathrm{D}$ in which $\mathrm{A}=5 \mathrm{ft}, \mathrm{B}=10 \mathrm{ft}$, $\mathrm{C}=15 \mathrm{ft} \& \mathrm{D}=20 \mathrm{ft}$ were prepared and complete measurements of these are mentioned in (Supplementary Table 2).

In Supplementary Table 2, a common pattern was observed in hole diameter, with an increase in distance, bullet hole diameter size

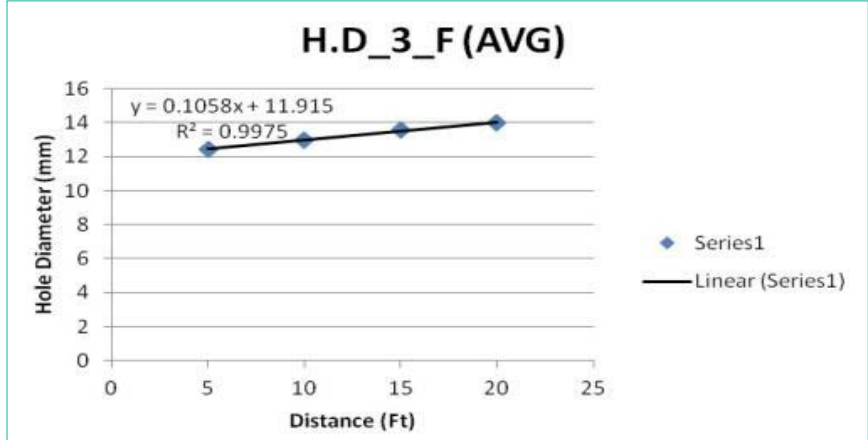

Figure 10: The $x$-axis gives each of the four distances. $A=5 \mathrm{ft}, B=10 \mathrm{ft}$, $\mathrm{C}=15 \mathrm{ft}, \mathrm{D}=20 \mathrm{ft}$ for AK-47 rifle (3). The points for $\mathrm{Y}$-axis displaying the hole diameter average value from front side of the laminated glass. The straight line represents the continuity \& increase in the measurements with respect to the distance.

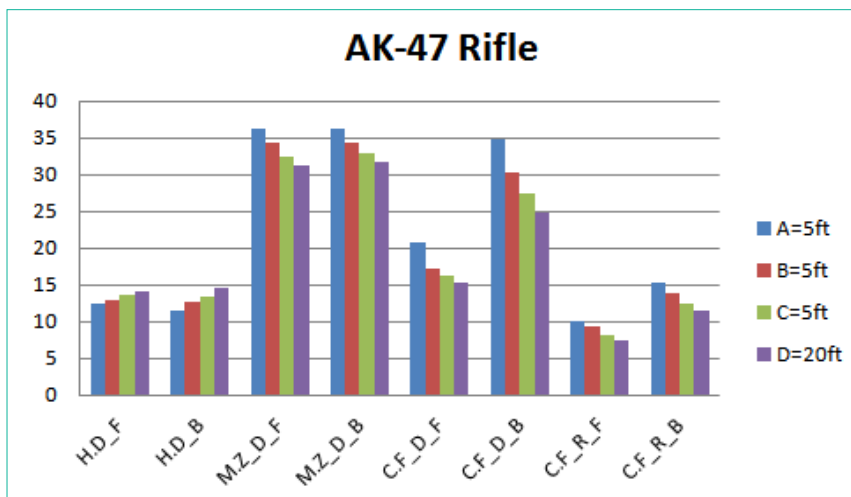

Figure 11: On $\mathrm{x}$-axis four color (Blue, maroon, green, and purple) represents the distance $A=5 \mathrm{ft}, \mathrm{B}=10 \mathrm{ft}, \mathrm{C}=15 \mathrm{ft}, \mathrm{D}=20 \mathrm{ft}$ respectively. On $\mathrm{y}$-axis each parameter measurements in $\mathrm{mm}$ (supplementary) from front and the back sides are considered against all the four distances.

also increases. This analysis is constant with (1) pistol results for both sides of the glass, hence enhancing the reliability on this feature for distance determination. Rest of the measurements was also consistent in pattern with .30 bore pistol results. All the interpretations are presented in (Supplementary Table 2).

Comparison: To check whether the dependencies of features are on distance and not on calibre, these bullet holes were prepared and compared to 3.3.1 measurements. For determining distance, the average of hole diameter from front and back was analyzed but only measurements of hole diameter from the front side for $9 \mathrm{~mm}$ are shown in Table 1. Average of bullet hole diameter from front side measurements were taken and mentioned in Table 1 and a consistent pattern was found in the increase of these measurements.

In Figure 8, data for hole diameter front, measurements for ammunition $9 \mathrm{~mm}$ pistol (2) on all four distances while angle was $90 \mathrm{o}$ (a) with the plane of target are shown. This consistency is coherent with the results shown in (Figure 6), hence verifying hole diameter is dependent on distance and not on calibre. To determine distance from bullet hole diameter measurements, an unknown value (x) can be plotted in this graph and respective distance for that value can be determined from it.

The bar chart represents the direct and inverse proportionality 


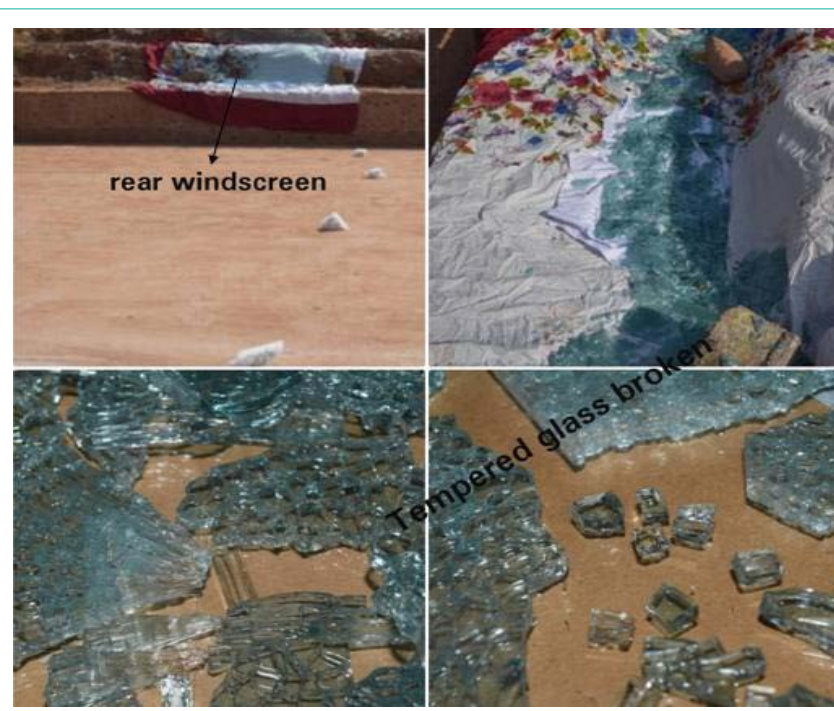

Figure 12: Top-left image displays Tempered glass before and Top-right image displays the shattered glass after the attempt of preparing bullet holes. Both of the bottom images represent the breaking pattern of the shattered glass pieces.

for each of the parameter measurements against all the four distances that were considered for $9 \mathrm{~mm}$ pistol. Clearly it was observed that while hole diameter front and back both were directly proportional to the increase in distance, other parameters like mist zone diameter front and back, cone fracture diameter front and back, cone fracture radius front and back respectively were inversely proportional to the increase in distance as shown in (Figure 9). Again the observations were consistent with .30 bore pistol results.

For ak-47: For distance determination, to verify the results of .30 bore pistol \& $9 \mathrm{~mm}$ pistol, another calibre AK-47 rifle was fired on all four distances: A, B, C \& D at $\alpha=90^{\circ}$. Bullet holes: $3 \alpha \mathrm{A}, 3 \alpha \mathrm{B}$, $3 \alpha \mathrm{C}, \& 3 \alpha \mathrm{D}$ in which $\mathrm{A}=5 \mathrm{ft}, \mathrm{B}=10 \mathrm{ft}, \mathrm{C}=15 \mathrm{ft} \& \mathrm{D}=20 \mathrm{ft}$ were prepared as shown in Figure 10 and complete measurements of these are mentioned in (Supplementary Table 2).

In Supplementary Table 2 a common pattern was noticed in hole diameter along with all other fracture measurements, this analysis is also constant with " 1 " \& " 2 " pistol results, hence enhancing the reliability on this feature for the distance determination.

Comparison: To check whether the dependency of features are on distance and not on calibre, these bullet holes were now prepared with rifle calibre and compared to 3.3.1 \& 3.3.2 pistol calibre measurements. For determining distance, the average of hole diameter from front and back was analyzed but only measurements of hole diameter from the front side for AK-47 rifle are shown in (Table 1). Average of bullet hole diameter from front side measurements were taken and mentioned in Supplementary Table 3 and a consistent pattern was found in an increase of these measurements, hence distance determination via hole diameter measurements is valid and verified.

In figure (Figure 10), evaluations for hole diameter front measurements for ammunition AK-47 rifle (3) on all four distances while angle was $90^{\circ}(\alpha)$ with the plane of the target are presented. This consistency is coherent with the results shown in Figures 6\&8, hence verifying hole diameter is dependent on the distance and not

Table 2: Observations of chi-square test.

\begin{tabular}{|c|c|}
\hline \multicolumn{2}{|l|}{ Chi Square Observations } \\
\hline \multicolumn{2}{|c|}{$\mathrm{H}_{\mathrm{o}}$ : Change in distance will produce different impact and fracture pattern on the glass for same calibre on same angle. } \\
\hline \multicolumn{2}{|l|}{ FOR .30 BORE } \\
\hline Total No of observations (n) & 6 \\
\hline Degree of Freedom (n-1) & $6-1=5$ \\
\hline $\begin{array}{l}\text { Tabulated value of Chi-square distribution for } 5 \text { degree of freedom at } 0.05 \text { level of } \\
\text { significance }\end{array}$ & 11.07 \\
\hline Calculated Value of chi-square & 0.999773 \\
\hline Conclusion & $\begin{array}{l}\text { Calculated value of } X^{2}<\text { tabulated value; hence null hypothesis can't be } \\
\text { rejected }\end{array}$ \\
\hline \multicolumn{2}{|l|}{ FOR $9 \mathrm{~mm}$} \\
\hline Total No of observations (n) & 6 \\
\hline Degree of Freedom $(n-1)$ & $6-1=5$ \\
\hline $\begin{array}{l}\text { Tabulated value of Chi-square distribution for } 5 \text { degree of freedom at } 0.05 \text { level of } \\
\text { significance }\end{array}$ & 11.07 \\
\hline Calculated Value of chi-square & 0.999997 \\
\hline Conclusion & $\begin{array}{l}\text { Calculated value of } X^{2}<\text { tabulated value; hence null hypothesis can't be } \\
\text { rejected }\end{array}$ \\
\hline \multicolumn{2}{|l|}{ FOR AK-47 } \\
\hline Total No of observations ( $\mathrm{n})$ & 6 \\
\hline Degree of Freedom $(n-1)$ & $6-1=5$ \\
\hline $\begin{array}{l}\text { Tabulated value of Chi-square distribution for } 5 \text { degree of freedom at } 0.05 \text { level of } \\
\text { significance }\end{array}$ & 11.07 \\
\hline Calculated Value of chi-square & 0.999883 \\
\hline Conclusion & $\begin{array}{l}\text { Calculated value of } X^{2}<\text { tabulated value; hence null hypothesis can't be } \\
\text { rejected }\end{array}$ \\
\hline
\end{tabular}


on the calibre. To determine distance from bullet hole diameter measurements, an unknown value $(\mathrm{x})$ can be plotted in this graph and respective distance for that value can be determined from it. Continuity \& increase in the measurements with respect to the distance.

The bar chart represents the direct and inverse proportionality for each of the parameter measurements against all the four distances that were considered for AK-47 rifle. Clearly it was observed that while hole diameter front and back both were directly proportional to the increase in distance, other parameters like mist zone diameter front and back, cone fracture diameter front and back, cone fracture radius front and back respectively were inversely proportional to the increase in distance as shown in (Figure 11). Again the observations were consistent with .30 bore pistol and $9 \mathrm{~mm}$ pistol results.

On the basis of observations of all the laminated screens, it is observed that measurements of hole diameter shows a consistency that can be observed in the above graphs and has been proved in the Chi Square Observations. Parameters that were measured against a bullet hole are taken as count of no. of observations. These all values are summarized in Table 2.

\section{Tempered glass analysis}

For preparing bullet holes from all four distances, whenever a fire was shot; regardless of calibre, or velocity of a firearm, the tempered glass couldn't endure the thrust of the projectile and it breaks into small pieces as shown in (Figure 12).

The breaking pattern of whole glass is the same i.e., it breaks into small pieces which on collecting them continues to break into smaller, equal proportioned pieces. The glass pieces were evidently so small that collection of these pieces was unrealistic and taking measurements on them was out of question.

Rib marks were present on larger pieces but they are only feasible to study under some conditions. For example, glass pieces are not moved from the original position or if moved, they shall be treated with so much care to avoid further breakage of the glass piece. In that case, the direction of force applied can be determined but that as well can be studied on larger pieces that are very limited, due to which information gathered will be incomplete.

Hole pattern can be judged where mist zone appears on the glass but then again it also breaks in such small pieces that determination of distance was not possible. Measurements and measurements of hole diameter, cone fractures or count for radial and concentric fractures were unworkable as no hole could be identified. For this reason, results could not be concluded from tempered glass, hence no table and graphs were presented for tempered glass.

\section{Discussion}

Investigating bullet hole via glass fracture analysis is one of the methods to decipher the crime scenes. Fractography (fracture analysis) for glass has a lot of dimensions that can be studied and solving cases related to firing on vehicles can be improved with its help. For determining distance on laminated and tempered glass this research was conducted. For laminated glass if calibre and angle is known then distance can be calculated as it is shown in our results.
For determination of distance of bullet holes on glass the data was measured, calculated and observed. Data was observed keenly and noted for all the parameters of glass fractures, amongst which radial fractures count, concentric fractures count, were to some extent dependent on factors other than distance. Those factors can be glass type, glass width, firearm manufacturer, ammunition used, quality and quantity of gunpowder, and surface area of the windscreen on which bullet hole has been made. For this reason, analysis of those parameters was taken into consideration, which was dependent only on distance. Parameters that were under consideration to conclude the results were hole diameter, and cone fractures diameter from both sides of the glass.

For distance determination, a uniform pattern in hole diameter data was examined of our prepared .30 bore pistol bullet holes. The hole diameter was varying according to the distance. With an increase in distance, the bullet hole diameter was also increasing. To verify this pattern, bullet holes were also prepared from $9 \mathrm{~mm}$ pistol on the same distances. To validate both of their pattern consistency, bullet holes were now prepared from high-velocity calibre AK-47 rifle and the resulting pattern was same. So it was concluded that to determine distance from unknown value of hole diameter when calibre and angle are known, hole diameter value can be plotted in the respective graph and distance can be determined.

For tempered glass, after test fire is performed to prepare bullet hole; gathering information or measurements to observe and analyze them was not possible. It was unlikely to calculate any of the measurements including hole diameter, cone fracture diameter, cone fractures radius, count of radial fractures, count for concentric fracture. Rib marks were present on the cross-sectional area of the glass piece but they can only determine the direction of force applied. As there was no data from the glass, that's why for tempered glass it was not credible to determine distance via glass fracture analysis.

Glass fracture analysis on annealed and heat strengthened glass had much spotlight and detailed work had been done on it through these years but laminated glass is not studied that much. This study is specific to automobile glass and its pattern analysis still had a lot of areas to cover. This research is although able to determine distance if angle and calibre are known, but there is always room for improvement. Our research was focused on distance of fire but for future goals, many aspects related to this topic can be studied. In the subsequent studies, investigation of distance keeping calibre and angle constant with different manufacturer's weapons of same ammunition and its comparison can be done. While keeping firearm same, just changing ammunition of different companies that are available in our area commonly and comparing their results. Further analysis can be done by changing the nature of a projectile for the same automobile glass. This research can be broadened by even keeping ammunition constant and just vary target; i.e., a laminated glass of different automobile companies and comparing its effects. Most importantly, this research was done for constant target. While mostly cases of armed violence for automobiles involves moving target so to take this forward; determination of distance of bullet holes for moving target can be done.

\section{Conclusion}

This research was conducted to determine the distance of 
bullet hole from the shooter. Underneath the optimized values of experimental parameter; determination of distance was conducted. For laminated glass, measurements were to be measured, observed and analyzed from both sides of the glass. For tempered glass, to obtain results was not possible.

The obtained results showed that distance determination is possible when calibre and angle are known. In order to know distance for bullet holes of .30 bore pistol, hole diameter measurements can be plotted in the respective graph and distance of fire can be determined. Similarly, bullet hole of $9 \mathrm{~mm}$ pistol, hole diameter reading can also be plotted in its respective graph to determine its distance. In the same way to determine distance for bullet hole of AK47 rifle, measurements can be plotted into its respective graph. These graphical representations for distance determination are valid with error of $\pm 5 \mathrm{ft}$, when values taken into consideration are bullet hole diameter against the firearms used in this research.

The determination of distance was related to the factors and parameters used in this research and also to some other environmental factors. If factors or parameters are changed then resulting observations and results will also change accordingly. These findings can be supportive of forensic criminal investigations along with new related detective parameters for researchers. Bullet holes investigation to determine these factors with the help of fracture analysis can be helpful to construct rational judgment by interpreting the evidence, for forensic investigations.

\section{Acknowledgment}

This research was conducted in National Forensic Science Agency, Islamabad, Pakistan under the supervision of Head of Firearms department Mr. Ali. Authors acknowledge for providing facilities and sources along with the support and encouragement for this research. Authors will like to thank Mr. Nadeem Ahmad, and Ms.
Aaliya Malik of Firearms and Tool marks department for their fruitful discussions and support throughout the research, whether it be help in preparation of experimental process, conducting experiment or be an encouragement at any step. Mr Waheed Anwar of Fingerprint department has also provided his photography skills along with his critique assessment throughout the process and authors profoundly regard his efforts. For experiment conduction authors are thankful to Police Line ICT, Pakistan for letting us use their firing range. Authors would also like to appreciate the input of Mr Rameez for helping in getting the materials for the experiment.

\section{References}

1. Tryhorn FG. Examination of Glass. Journal of Criminal Law and Criminology. $1939 ; 30$.

2. Harshey A, Srivastava A, Yadav VK, Nigam K, Kumar A, Das T. Analysis of glass fracture pattern made by $.177^{\prime \prime}(4.5 \mathrm{~mm})$ Caliber air rifle. Egyptian Journal of Forensic Sciences. 2017; 7: 20.

3. Bradt RC. The Fractography and Crack Patterns of Broken Glass. Journal of Failure Analysis and Prevention. 2011; 11: 79-96.

4. Ansari Md, Anupam C. Influence of projectile nose shape and incidence angle on the ballistic perforation of laminated glass fiber composite plate. Composites Science and Technology. 2017; 142: 107-116.

5. Abhyankar S, Srivastava A, Yadav VK, Nigam K, Harshey A. Glass Fractures Made from Different Pellet Shapes- A Preliminary Study. Journal of Forensic Science and Criminal Investigation. 2018; 8.

6. Tiwari N, Harshey A, Das T, Abhyankar S, Yadav VK, Nigam K, et al. Evidential significane of multiple fracture pattern on the glass in forensic ballistics. Egyptian Journal of Forensic Science. 2019; 9: 22.

7. Waghmare NP. Distinctive Impact Pattern of Ak 47/56 Projectile on Glass Fracture. Journal of Forensic Sciences \& Criminal Investigation. 2018; 8.

8. Stevenage Glass Company Ltd. Stevenage Glass Company. 1966.

9. Springshare. Corning museum of glass. 2020. 